\title{
Comparison of Heat Transfer Conditions in Tube Bundle Cross-Flow for Different Tube Shapes
}

Dr. Andrej Horvat, research associate*

Jožef Stefan Institute, Reactor Engineering Division

Jamova 39, SI 1001, Ljubljana, Slovenia

Phone: +386 (0)1 5885-450, Fax: +386 (0)1 5885-377

E-mail: andrej.horvat@ijs.si

* Currently at ANSYS Europe Ltd.

West Central 127, Milton Park, Abingdon, OX14 4SA, UK

Phone: +44 (0)870 142 0267, Fax: +44 (0)870 1420301

E-mail: andrej.horvat@ansys.com

Dr. Matjaž Leskovar, research associate

Jožef Stefan Institute, Reactor Engineering Division

Jamova 39, SI 1001, Ljubljana, Slovenia

Phone: +386 (0)1 5885-450, Fax: +386 (0)1 5885-377

E-mail: matjaz.leskovar@ijs.si

Dr. Borut Mavko, professor of nuclear engineering

Jožef Stefan Institute, Reactor Engineering Division

Jamova 39, SI 1001, Ljubljana, Slovenia

Phone: +386 (0)1 5885-450, Fax: +386 (0)1 5885-377

E-mail: borut.mavko@ijs.si 


\title{
Comparison of Heat Transfer Conditions in \\ Tube Bundle Cross-Flow for Different Tube Shapes
}

Andrej Horvat, Matjaž Leskovar, Borut Mavko

\begin{abstract}
Detailed transient numerical simulations of fluid and heat flow were performed for a number of heat exchanger segments with cylindrical, ellipsoidal and wing-shaped tubes in a staggered arrangement. The purpose of the analysis was to get an insight of local heat transfer and fluid flow conditions in a heat exchanger and to establish widely applicable drag coefficient and Stanton number correlations for the heat exchanger integral model, based on average flow variables. The simulation results revealed much more complex flow behavior than reported in current literature. For each of the almost 100 analyzed cases the time distributions of the Reynolds number, the drag coefficient and the Stanton number were recorded and their average values calculated. Based on these average values the drag coefficient and the Stanton number correlations were constructed as polynomial functions of the Reynolds number and the hydraulic diameter. The comparison of the collected results also allow more general conclusions on efficiency and stability of the heat transfer process in tube bundles.
\end{abstract}




\section{Nomenclature}

Latin letters

$a_{\mathrm{i}} \quad$ coefficients of the NACA wing polynomial

$a$ and $b$ maximum and minimum radius of the ellipsoidal tubes

$A_{f} \quad=V_{f} / l$, fluid flow cross-section

$A_{o} \quad$ wetted surface

$c \quad$ speed of sound, NACA wing chord length

$c_{p} \quad$ specific heat

$C_{d} \quad$ drag coefficient

d diameter

$d t \quad$ timestep

$d_{h} \quad=4 V_{f} / A_{o}$, hydraulic diameter

$F_{1} \quad$ blending function in the SST model

$k \quad$ turbulence kinetic energy

$p \quad$ pitch between tubes, pressure

Pr Prandtl number

Re Reynolds number

REV representative elementary volume

$S \quad$ tube cross-section

St Stanton number

$T \quad$ temperature

$t \quad$ time, NACA wing thickness

$t_{\text {scale }} \quad$ average time needed for a flow particle to pass the simulation domain

$u \quad$ streamwise velocity

v velocity

V volume 


$$
\begin{array}{ll}
V_{f} & \text { fluid volume in REV } \\
y^{+} & \text {non-dimensional wall distance }
\end{array}
$$

\section{Greek letters}

$\begin{array}{ll}\varepsilon & \text { turbulence dissipation rate } \\ \lambda & \text { thermal conductivity } \\ \mu & \text { dynamic viscosity } \\ \rho & \text { density } \\ \omega & \text { turbulence frequency } \\ \text { Subscript/Superscript } \\ f & \text { fluid phase } \\ s & \text { solid phase } \\ t & \text { turbulence model variable } \\ w a l l & \text { wall conditions } \\ x & \text { streamwise direction } \\ y & \text { horizontal spanwise direction } \\ z & \text { vertical spanwise direction }\end{array}$

\section{Introduction}

Heat exchangers are found in different industrial sectors where heat has to be transferred between different media. For the optimal design of a heat exchanger, and for the determination of its operational parameters and performance, the drag and heat transfer between the fluid flow and the structure have to be known. The characteristics of a heat exchanger can be established either directly by experimental measurements (e.g. Žukauskas et al., 1987, Kays \& London, 1998, Kakac, 1985, and Aiba et al., 1982) or by numerical simulations using different 
mathematical models (e.g. Launder \& Massey, 1978, Antonopoulos, 1979, Beale \& Spalding, 1999, and Barsamian \& Hassan, 1997). We are mentioning only few references as it is impossible to justly evaluate work of all investigators who made important contributions.

The drawback of experimental studies is that they are time and cost consuming and, therefore, not best suited for a comprehensive parametrical analysis of different heat exchanger prototypes. Nevertheless, such analyses are needed in development of new heat exchanger designs, and for establishment of their optimal operational parameters. Therefore, as a complement to experimental work, different numerical methods and approaches are increasingly employed for the assessment of heat exchanger characteristics.

Direct numerical simulations of fluid flow and heat transfer in heat exchangers are today, despite the fast progress in computer performance, computationally still too demanding. Therefore, significant modeling simplifications have to be done. The most commonly used approach is to simplify the turbulence modeling and the wall effect treatment. Horvat and Mavko (2005) studied an alternative approach, which is based on hierarchic modeling, where the model and its computation are split onto two distinct levels. On the first level, detailed transient threedimensional numerical simulations of fluid flow and heat transfer in a geometry similar to a heat exchanger segment are performed to study the local thermo-hydraulic behavior. Based on the calculated three-dimensional velocity and temperature distributions, dependencies of the drag coefficient and the heat transfer coefficient on average flow parameters are determined. On the second level, a simplified integral model (Horvat \& Catton, 2003), which is based on average flow variables, is applied to simulate the heat transfer over a whole heat exchanger using the established drag coefficient and heat transfer coefficient correlations. The use of the two-level hierarchic modeling approach has some clear advantages. As the computationally most demanding terms of momentum and heat transport are determined on a separate level, the 
integral code is fast running, but still capable to accurately predict the heat flow for a whole heat exchanger. The accuracy of the heat exchanger integral model and its applicability crucially depends on the accuracy of the used drag and heat transfer coefficient functions, and the range of the heat exchanger geometrical and the flow parameters, which are covered by these functions.

The main purpose of the performed work is to get a detailed insight of the local heat transfer and fluid flow conditions in different tube bundles, and to establish widely applicable drag and heat transfer coefficient functions for the heat exchanger integral model (Horvat \& Catton, 2003). Three different tube shapes were analyzed: the cylindrical, the ellipsoidal and the wing shape. In the performed parametric analysis the considered fluid flow Reynolds numbers cover the laminar, the transitional as well as the turbulent flow regime. The range of the tubes pitch-todiameter ratio in the staggered arrangement was from 1.125 to 2.0. For each performed numerical simulation, the time averaged drag coefficient $\bar{C}_{d}$ and Stanton number $\overline{S t}$ were calculated. Based on these calculated discrete values, the analytical functions $\bar{C}_{d}\left(d_{h}, \overline{R e}\right)$ and $\overline{S t}\left(d_{h}, \overline{R e}\right)$ were established as polynomial functions of the hydraulic diameter $d_{h}$, which was taken as the most representative geometrical parameter, and the time averaged Reynolds number $\overline{R e}$.

\section{Geometrical models}

For each heat exchanger tube bundle geometry, the numerical simulations were performed for a representative elementary volume (REV) of the tube bundle. The examples are presented in Figs. 1-3. As may be seen in figures, each bundle consists of tubes in staggered arrangement with a constant cross-section. 
The optimal size and shape of the REV was determined after extensive testing, considering the overall flow dynamics in the simulation domain, the error introduced due to the limited simulation domain, and the needed computational resources. It turned out that in order to get representative and reliable results it is more important to simulate longer time intervals than to enlarge the simulation domain.

To determine the influence of the tubes' shape on the heat exchanger characteristics, three different tube shapes were included in the analysis: the cylindrical, the ellipsoidal and the wing shape. In all cases the height of REV was equal to its diagonal pitch.

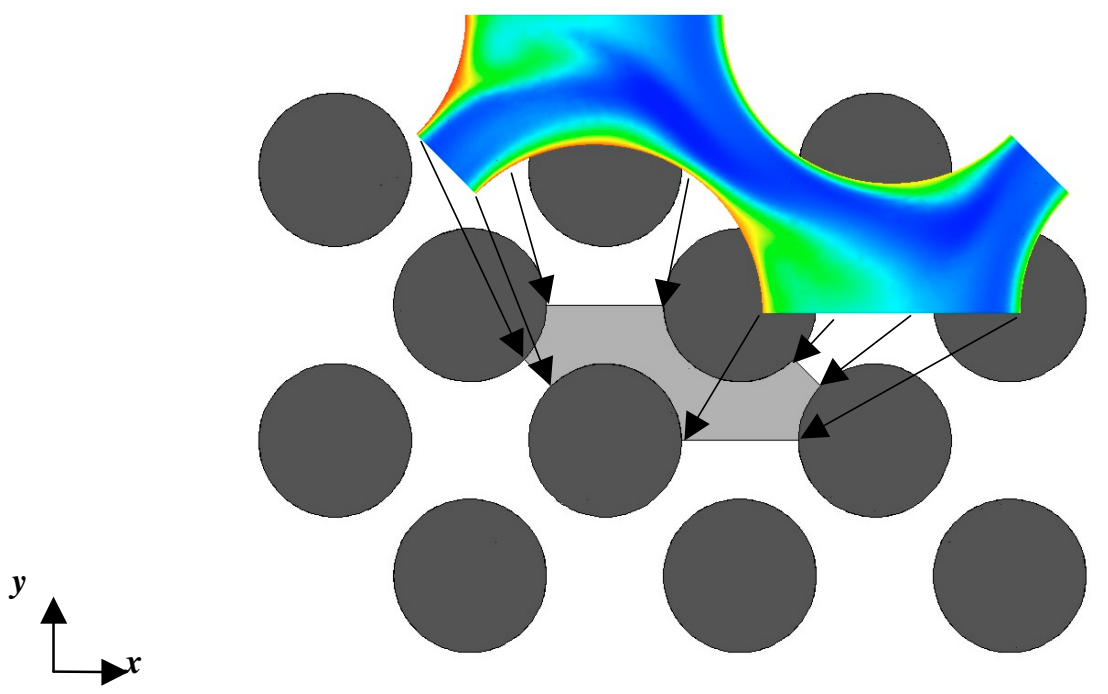

Figure 1: Heat exchanger tube bundle geometry with cylindrical tubes; instantaneous temperature field $304.4 \mathrm{~K} \leq T \leq 308.2 \mathrm{~K}, p / d=1.25$.

The diameter of the cylindrical tubes was chosen to be $3 / 8$ " (9.525 mm). The segments with the ellipsoidal and the wing form of tubes were designed to have the same fractions of the fluid phase and the solid structure as the segments with the cylindrical tubes:

$$
V_{f, c y l}=V_{f, \text { ell }}=V_{f, \text { wing }} \text { and } V_{s, \text { cyl }}=V_{s, \text { ell }}=V_{s, \text { wing }} \text {. }
$$




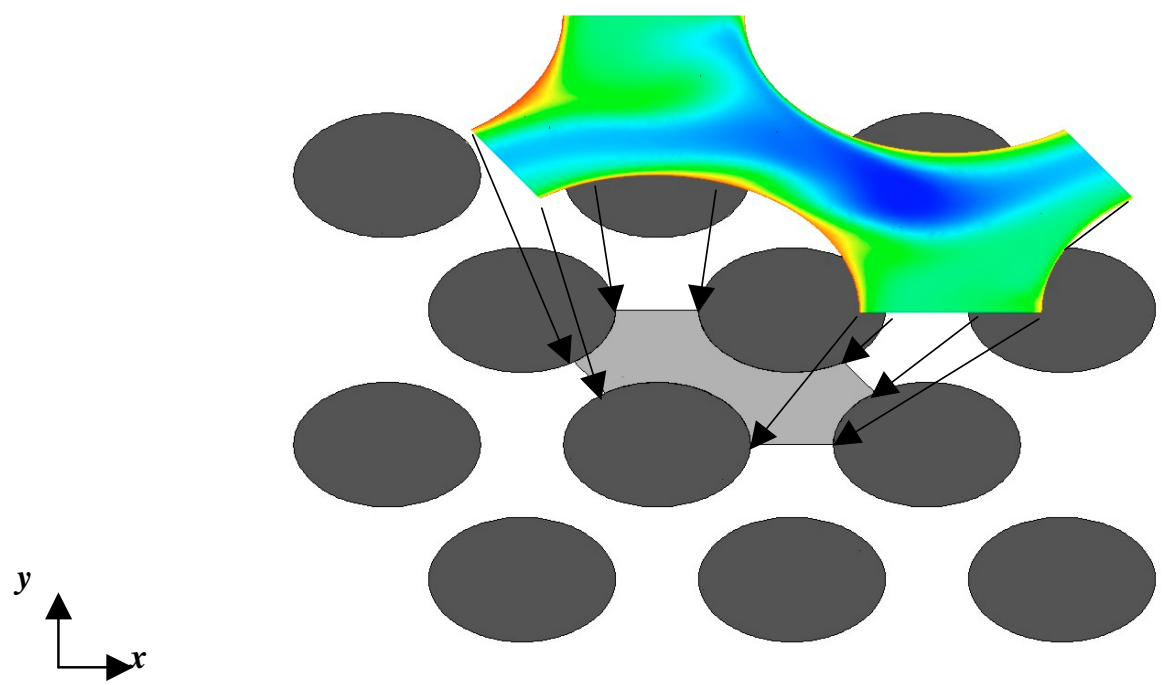

Figure 2: Heat exchanger tube bundle geometry with elliptical tubes; instantaneous temperature field $302.1 \mathrm{~K} \leq T \leq 308.2 \mathrm{~K}, p / d=1.25$.

The ellipsoidal tubes were designed with the ratio $1: 1.5$ between the maximum and the minimum radius ( $a$ and $b$ ). Based on this aspect ratio, both radii of the ellipsoidal tubes can be calculated from the requirement (1), which implies that the cross-sections of the cylindrical $S_{c y l}$ and the ellipsoidal $S_{\text {ell }}$ tubes have to be the same $S_{c y l}=S_{\text {ell }}$ :

$$
\frac{\pi d^{2}}{4}=\pi a b \Rightarrow a=\sqrt{\frac{3}{2}} \frac{d}{2}, \quad b=\sqrt{\frac{2}{3}} \frac{d}{2} .
$$

The shape of the wing form tubes was based on the NACA 4-digit-series of profiles e.g. NACA0020, where the last two digits represent the thickness-to-chord ratio $t / c$ (Ladson et al., 1996). In general, the NACA profile coordinates are calculated as

$$
\frac{y}{c}=a_{0}\left(\frac{x}{c}\right)^{1 / 2}+a_{1}\left(\frac{x}{c}\right)+a_{2}\left(\frac{x}{c}\right)^{2}+a_{3}\left(\frac{x}{c}\right)^{3}+a_{4}\left(\frac{x}{c}\right)^{4} .
$$

For $t / c=1 / 5$, the coefficients are given by Ladson et al. (1996):

$$
a_{0}=0.2969, a_{1}=-0.126, a_{2}=-0.3516, a_{3}=0.2843, a_{4}=-0.1015 \text {. }
$$




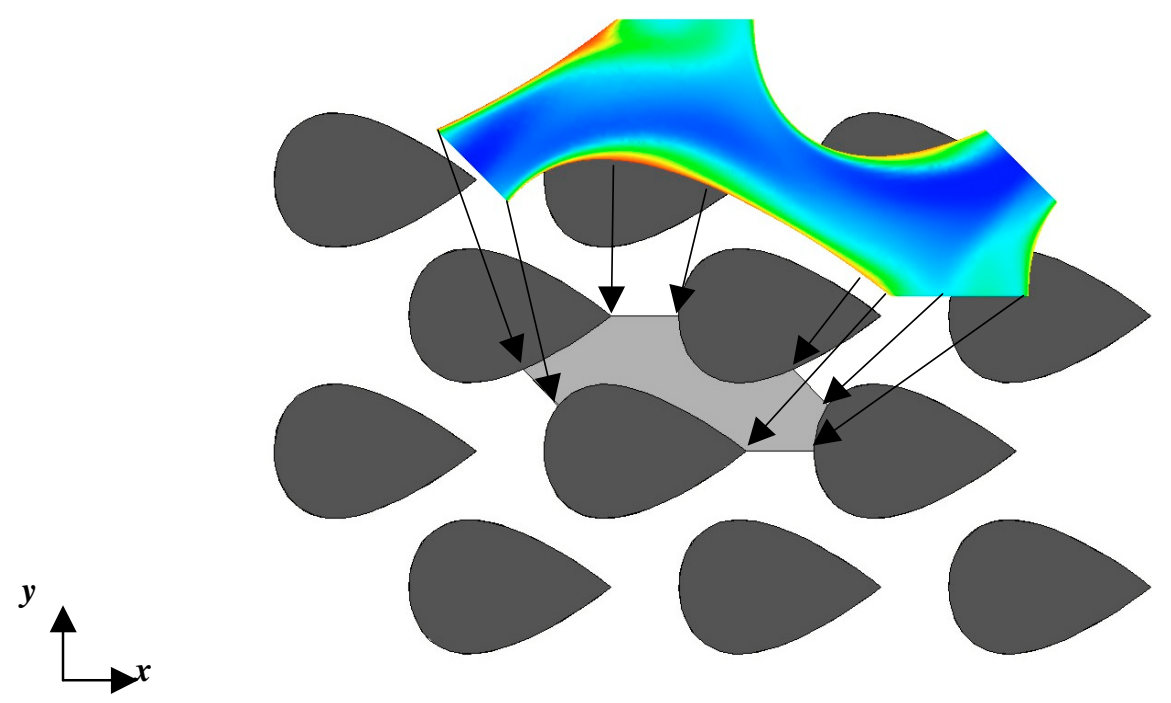

Figure 3: Heat exchanger tube bundle geometry with wing-shaped tubes; instantaneous temperature field $302.2 \mathrm{~K} \leq T \leq 308.2 \mathrm{~K}, p / d=1.25$.

To obtain segments with the same fraction of the fluid and the solid phase as for the cylindrical tubes, $t / c$ was increased to $2 / 3$. Therefore, the ordinates $y$ in function (3) were multiplied by $(2 / 3) /(1 / 5)$. The length of the chord $c$ was determined from the requirement (1), which implies that the cross-sections of the cylindrical tubes $S_{c y l}$ and the tubes with the wing shape $S_{\text {wing }}$ have to be the same $S_{c y l}=S_{\text {wing }}$.

For each shape of the tubes, the simulations were performed for 4 bundle geometries with different values of the diagonal pitch-to-diameter ratio: $p / d=1.125,1.25,1.5$ and 2.0 . So altogether 12 heat exchanger geometrical models were investigated, 4 with cylindrical tubes, 4 with ellipsoidal tubes and 4 with wing-shaped tubes. The analysis was limited to the bundle arrangements where the pitch in the $x$-direction $p_{x}$ is equal to the pitch in the $y$-direction $p_{y}$.

To establish the analytical drag coefficient and Stanton number functions, which are needed for the heat exchanger integral model, a representative geometrical parameter has to be identified. It 
was concluded that the hydraulic diameter $d_{h}$ more universally describes the heat exchanger geometrical conditions than the pitch-to-diameter ratio $p / d$. Therefore, the hydraulic diameter $d_{h}$ was chosen as the representative geometrical parameter. In Table 1 the calculated hydraulic diameters $d_{h}$ for all analyzed tube bundle geometries are presented.

Table 1: Hydraulic diameters $d_{h}$ for the analyzed tube bundle geometries.

\begin{tabular}{|c|c|c|c|}
\hline \multirow{2}{*}{$\begin{array}{c}\text { Ratio } \\
\text { p/d }\end{array}$} & \multicolumn{3}{|c|}{ Hydraulic diameter $\boldsymbol{d}_{\boldsymbol{h}}(\mathrm{cm})$} \\
\cline { 2 - 4 } & cylindrical shape & ellipsoidal shape & wing shape \\
\hline $\mathbf{1 . 1 2 5}$ & 0.5824 & 0.5649 & 0.5413 \\
\hline $\mathbf{1 . 2 5}$ & 0.9424 & 0.9142 & 0.7382 \\
\hline $\mathbf{1 . 5}$ & 1.776 & 1.723 & 1.638 \\
\hline $\mathbf{2 . 0}$ & 3.899 & 3.782 & 3.594 \\
\hline
\end{tabular}

\section{Mathematical model}

The transient numerical simulations of the fluid flow and heat transfer in the REV of the analyzed tube bundle geometries were performed with the CFX 5.7 commercial code. For the working fluid, material properties of air were taken. In the simulated cases, the maximum flow speed remains much lower than the speed of sound and the maximum variations of air temperature are only a few degrees. Therefore, the incompressible flow model was selected. 
Since the description of the basic conservation equations (mass, momentum and thermal energy) used in the CFX code can be found in any classical fluid dynamics textbook (e.g. Bird et al., 1960), it is not repeated here.

The tube walls in REV were treated as isothermal with the temperature $T_{\text {wall }}=35^{\circ} \mathrm{C}$. To allow disturbances to propagate over the geometrical limits of the simulation domain, the periodic boundary conditions were assigned in all 3 directions for all other boundaries.

\subsection{Momentum transport}

In order to consistently model the unsteady flow, periodicity has to be imposed on the transport equations in the streamwise direction. In the momentum equation, periodicity was achieved by separating an average pressure drop $\Delta p$ across the simulation domain from its residual part $p^{*}$ :

$$
p=p^{*}-x\left(\frac{\Delta p}{2 p_{x}}\right)
$$

Thus, the momentum equation can be written as

$$
\partial_{t}\left(\rho v_{i}\right)+\partial_{j} v_{j}\left(\rho v_{i}\right)=-\partial_{j} p^{*} \delta_{i j}+\partial_{j}\left(\mu \partial_{j} v_{i}\right)+\left(\frac{\Delta p}{2 p_{x}}\right) \delta_{i, x}+\partial_{j}\left(\mu_{t} \partial_{j} v_{i}\right)-\frac{2}{3} \rho k \delta_{i j}
$$

The simulations were performed for a number of preset values of the pressure drop $\Delta p$ along the simulation domain, as presented in Table 2. For all three analyzed tube shapes, the same values of the pressure drops were chosen. 
Table 2: Imposed pressure drop $\Delta p$ along the simulation domain.

\begin{tabular}{|c|c|c|c|c|c|c|c|c|}
\hline \multirow{2}{*}{$\begin{array}{c}\text { Ratio } \\
\boldsymbol{p} / \boldsymbol{d}\end{array}$} & \multicolumn{7}{|c|}{ Pressure drop $\Delta p($ Pa) } \\
\cline { 2 - 9 } & Case 1 & Case 2 & Case 3 & Case 4 & Case 5 & Case 6 & Case 7 & Case 8 \\
\hline $\mathbf{1 . 1 2 5}$ & 2.5 & 5.0 & 10.0 & 20.0 & 40.0 & 80.0 & 160.0 & $/$ \\
\hline $\mathbf{1 . 2 5}$ & 0.5 & 1.0 & 2.0 & 4.0 & 8.0 & 16.0 & 24.0 & 32.0 \\
\hline $\mathbf{1 . 5}$ & 0.125 & 0.25 & 0.5 & 1.0 & 2.0 & 4.0 & 6.0 & 8.0 \\
\hline $\mathbf{2 . 0}$ & 0.015625 & 0.03125 & 0.0625 & 0.125 & 0.25 & 0.5 & 0.75 & 1.0 \\
\hline
\end{tabular}

\subsection{Energy transport}

In the energy equation, the periodicity of temperature field was implemented by separating the average temperature increase $\Delta T$ along the simulation domain from its residual part $T^{*}$ :

$$
T=T^{*}+x\left(\frac{\Delta T}{2 p_{x}}\right)
$$

The energy transport equation changes its form to:

$$
\partial_{t}\left(\rho c_{p} T^{*}\right)+\partial_{j} v_{j}\left(\rho c_{p} T^{*}\right)=\partial_{j}\left(\lambda \partial_{j} T^{*}\right)-\rho c_{p} v_{j}\left(\frac{\Delta T}{2 p_{x}}\right) \delta_{x, j}+\partial_{j}\left(\frac{\mu_{t}}{P r_{t}} \partial_{j} c_{p} T^{*}\right)
$$

where the periodic boundary condition are applied to the residual temperature part $T^{*}$. Consequently, the isothermal boundary conditions are also converted to

$$
T_{\text {wall }}^{*}=T_{\text {wall }}-x\left(\frac{\Delta T}{2 p_{x}}\right) .
$$

In order to preserve the validity of the assumption of constant material properties, the average temperature increase was set to $\Delta T=1^{\circ} \mathrm{C}$ for all simulations. 


\subsection{Turbulence transport}

The turbulence stresses and the turbulence viscosity $\mu_{t}$ were calculated with the transient shear stress transport (SST) model, which was developed and improved by Menter (1993). It is a combination of the $k-\varepsilon$ and the $k-\omega$ model of Wilcox (1986). At the wall, the turbulence frequency $\omega$ is much more precisely defined than the turbulence dissipation rate $\varepsilon$. Therefore, the SST model activates the Wilcox model in the near-wall region by setting the blending function $F_{1}$ to 1.0. Far away from the wall, $F_{1}$ is 0.0 , thus activating the $k$ - $\varepsilon$ model for the rest of the flow field:

$$
\mathrm{SST} \text { model }=F_{1} \cdot(k-\omega \text { model })+\left(1-F_{1}\right) \cdot(k-\varepsilon \text { model }) .
$$

By switching between both models, the SST model gives similar, if not even superior performance than the low-Reynolds number $k$ - $\varepsilon$ models, but with much larger robustness. More details on the SST model can be found in Menter (1994).

\section{Computational details}

For each analyzed REV geometry, the optimal 3D numerical grid was generated, taking into account also the case specific fluid flow conditions. The numerical grids were built with tetrahedra and prisms, which were aligned with the tube walls to better describe the boundary layer structures. Since the numerical results can be grid dependent, special care was taken to construct numerical grids with sufficient resolution and uniformity. As the basic criterion for the numerical grid resolution, the maximum non-dimensional wall distance $y^{+}$of the first layer of nodes was taken. During the simulations, the maximum $y^{+}$did not exceed the value of 2.0. Tables 3-5 summarize the number of grid nodes used for the numerical simulations. 
Table 3: Number of grid nodes used in the REV with the cylindrical tubes.

\begin{tabular}{|c|r|r|r|r|r|r|r|c|}
\hline \multirow{2}{*}{$\begin{array}{c}\text { Ratio } \\
\text { p/d }\end{array}$} & \multicolumn{7}{|c|}{ Number of grid nodes } \\
\cline { 2 - 9 } & Case 1 & Case 2 & Case 3 & Case 4 & Case 5 & Case 6 & Case 7 & Case 8 \\
\hline $\mathbf{1 . 1 2 5}$ & 54811 & 54811 & 89428 & 89428 & 114500 & 173550 & 350245 & $/$ \\
\hline $\mathbf{1 . 2 5}$ & 71445 & 71445 & 71445 & 158669 & 158669 & 222296 & 222296 & 222296 \\
\hline $\mathbf{1 . 5}$ & 89525 & 89525 & 89525 & 89525 & 180002 & 180002 & 180002 & 180002 \\
\hline $\mathbf{2 . 0}$ & 79047 & 79047 & 79047 & 79047 & 79047 & 79047 & 116734 & 116734 \\
\hline
\end{tabular}

Table 4: Number of grid nodes used in the REV with the elliptical tubes.

\begin{tabular}{|c|r|r|r|r|r|r|r|r|}
\hline \multirow{2}{*}{$\begin{array}{c}\text { Ratio } \\
\boldsymbol{p} / \boldsymbol{d}\end{array}$} & \multicolumn{7}{|c|}{ Number of grid nodes } \\
\cline { 2 - 9 } & Case 1 & Case 2 & Case 3 & Case 4 & Case 5 & Case 6 & Case 7 & Case 8 \\
\hline $\mathbf{1 . 1 2 5}$ & 57834 & 57834 & 57834 & 180618 & 180618 & 180618 & 213225 & $/$ \\
\hline $\mathbf{1 . 2 5}$ & 87097 & 87097 & 87097 & 87097 & 137600 & 205476 & 205476 & 205476 \\
\hline $\mathbf{1 . 5}$ & 119309 & 119309 & 119309 & 119309 & 119309 & 174752 & 174752 & 174752 \\
\hline $\mathbf{2 . 0}$ & 95641 & 95641 & 95641 & 95641 & 95641 & 186868 & 186868 & 186868 \\
\hline
\end{tabular}


Table 5: Number of grid nodes used in the REV with the wing-shaped tubes.

\begin{tabular}{|c|r|r|r|r|r|r|r|c|}
\hline \multirow{2}{*}{$\begin{array}{c}\text { Ratio } \\
\boldsymbol{p} / \boldsymbol{d}\end{array}$} & \multicolumn{7}{|c|}{ Number of grid nodes } \\
\cline { 2 - 9 } & Case 1 & Case 2 & Case 3 & Case 4 & Case 5 & Case 6 & Case 7 & Case 8 \\
\hline $\mathbf{1 . 1 2 5}$ & 82085 & 82085 & 199072 & 199072 & 199072 & 242780 & 242780 & $/$ \\
\hline $\mathbf{1 . 2 5}$ & 82085 & 82085 & 82085 & 82085 & 127330 & 127330 & 213557 & 213557 \\
\hline $\mathbf{1 . 5}$ & 128882 & 128882 & 128882 & 128882 & 128882 & 128882 & 202294 & 202294 \\
\hline $\mathbf{2 . 0}$ & 110054 & 110054 & 110054 & 110054 & 230884 & 230884 & 230884 & 230884 \\
\hline
\end{tabular}

In order to reduce the computational time required to reach thermal equilibrium, steady-state simulations on a coarser numerical mesh were performed first. After the thermal equilibrium was reached, the result file was used as initial conditions for further transient numerical simulations on a finer mesh. The timestep for the transient calculations was based on an average time interval needed for a flow particle to pass the simulation domain:

$$
t_{\text {scale }}=\frac{2 p_{x}}{u_{f}} \quad \text { and } \quad d t \leq \frac{t_{\text {scale }}}{80}
$$

\section{Results}

A comprehensive parametrical analysis of airflow and heat transfer in the REV was performed covering a wide spectrum of heat exchanger conditions. 
The following parameters were varied:

- Tube shape: cylindrical, ellipsoidal and wing shape tubes were considered (see Figs. 1-3).

- Pitch-to-diameter ratio: for each tube shape, 4 different pitch-to-diameter ratios were analyzed (see Table 1).

- Imposed pressure drop: for the each tube bundle geometry, the numerical simulations were performed for 7 or 8 imposed pressure drops (see Table 2).

Altogether 93 transient numerical simulations were performed. These simulations provided the necessary data to determine the drag coefficient and the Stanton number functions used in the heat exchanger integral model. The imposed pressure drops $\Delta p$ (Table 2) across REV generated flow which was in most cases unsteady. In order to extract relevant statistical values of physical variables, the volumetric average velocity

$$
u_{f}(t)=\frac{1}{V_{f}} \int_{\hat{V}_{f}} u\left(t, x_{i}\right) d V
$$

and temperature

$$
T_{f}(t)=\frac{1}{u_{f}(t) V_{f}} \int_{\hat{V}_{f}} u\left(t, x_{i}\right) T\left(t, x_{i}\right) d V
$$

were recorded at each timestep after statistical steady-state flow conditions were reached. The length of the recording interval was set on a case-by-case basis. We tried to find a repeatable pattern of flow behavior and adjust the recording interval to the pattern period to better capture the variable statistics. Therefore, the recording intervals were from 1200 to 4755 timesteps long. In all cases the recording interval was at least 150 times longer than the time required for an average flow particle to travel the length of the simulation domain (11). 
Using the obtained velocity distributions $u_{f}(t)$ and temperature distributions $T_{f}(t)$, the corresponding time distributions of the Reynolds number

$$
\operatorname{Re}(t)=\frac{\rho u_{f}(t) d_{h}}{\mu},
$$

the drag coefficient

$$
C_{d}(t)=\frac{2 \Delta p}{\rho u_{f}^{2}(t)}\left(\frac{A_{f}}{A_{o}}\right),
$$

and the Stanton number

$$
S t(t)=\frac{\Delta T}{T_{\text {wall }}-T_{f}(t)}\left(\frac{A_{f}}{A_{o}}\right)
$$

were calculated for the each simulated case. Further on, their time averages $\overline{R e}, \bar{C}_{d}$ and $\overline{S t}$, and their standard deviations $S_{R e}, S_{C d}$ and $S_{S t}$ were determined.

The presented numerical approach was validated by Horvat and Mavko (2005). The numerical results for the cylindrical tubes bundle with pitch-to-diameter ratio $p / d=1.5$ were compared to experimental data of Kays and London (1998) for a similar geometry with $p / d=1.414$. The comparison of the drag coefficient and the Stanton number distributions showed a good agreement between the calculated and the experimentally obtained values for the whole range of Reynolds numbers. The agreement demonstrates the correctness of the selected numerical approach.

\subsection{Drag coefficient functions}

The time distributions of Reynolds number $\operatorname{Re}(t)$ and drag coefficient $C_{d}(t)$ were obtained for the cylindrical, the ellipsoidal and the wing form of tube cross-sections and for the all imposed pressure drops. From the time distributions $\operatorname{Re}(t)$ and $C_{d}(t)$, the statistical average values $\overline{\operatorname{Re}}$ 
and $\bar{C}_{d}$ were calculated. Using least-square polynomial regression, the drag coefficient functions $\bar{C}_{d}\left(d_{h}, \overline{R e}\right)$ were determined from the calculated set of $d_{h}, \overline{R e}$ and $\bar{C}_{d}$ for the each form of tube cross-sections. The following drag coefficient approximation functions were obtained:

- Cylindrical tubes

$$
\begin{aligned}
\bar{C}_{d}\left(d_{h}, \overline{R e}\right)=0.2353 & +3.222 \cdot 10^{-10} d_{h}^{-4}+1.348 d_{h}^{1 / 2} \\
& +64.47 \overline{\operatorname{Re}}^{-1}-1.855 \cdot 10^{-5} \overline{\operatorname{Re}}-2.118 \cdot 10^{-9} \overline{\operatorname{Re}}^{2}
\end{aligned}
$$

- Ellipsoidal tubes

$$
\bar{C}_{d}\left(d_{h}, \overline{R e}\right)=0.03050+5.724 \cdot 10^{-4} d_{h}^{-1}+0.8838 d_{h}^{1 / 2}+64.30 \overline{R e}^{-1}-5.826 \cdot 10^{-4} \overline{R e}^{1 / 2}
$$

- Wing-shaped tubes

$$
\begin{aligned}
\bar{C}_{d}\left(d_{h}, \overline{R e}\right)=- & 0.3020+1.825 \cdot 10^{-10} d_{h}^{-4}+3.854 d_{h}^{1 / 2} \\
& +2.875 \overline{\operatorname{Re}}^{-1}-6.518 \cdot 10^{-7} \overline{\operatorname{Re}}-7.158 \cdot 10^{-13} \overline{\operatorname{Re}}^{3}
\end{aligned}
$$

Figures 4-6 present contour plots of the drag coefficient polynomials for the cylindrical (17), the ellipsoidal (18) and the wing (19) form of tube cross-sections. 


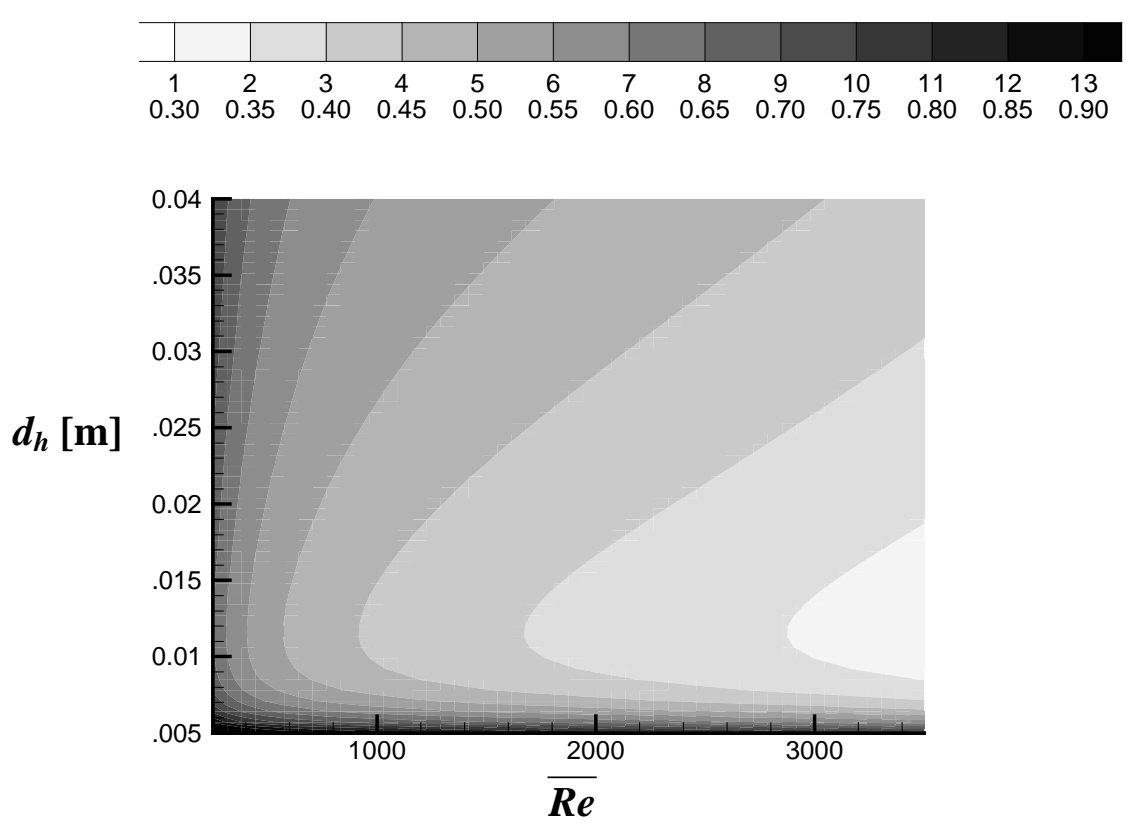

Figure 4: Drag coefficient polynomial function (17) for the cylindrical tubes.
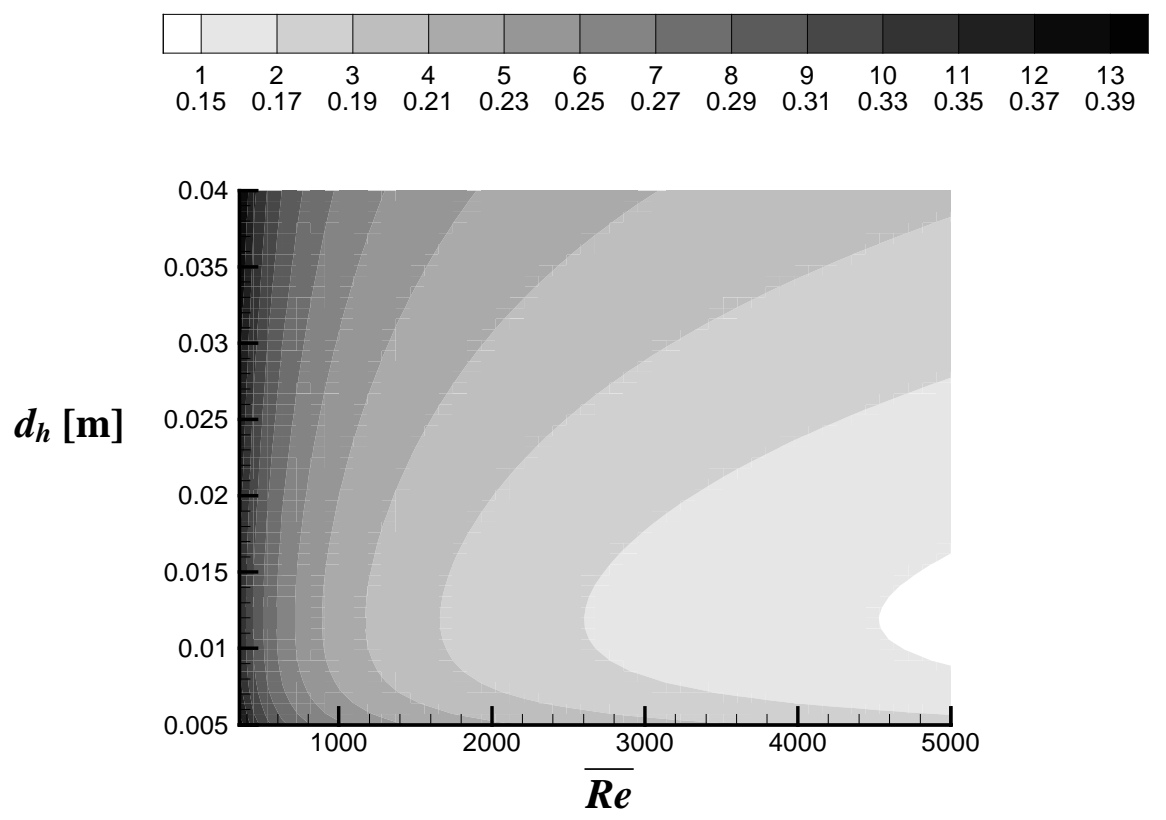

Figure 5: Drag coefficient polynomial function (18) for the ellipsoidal tubes. 


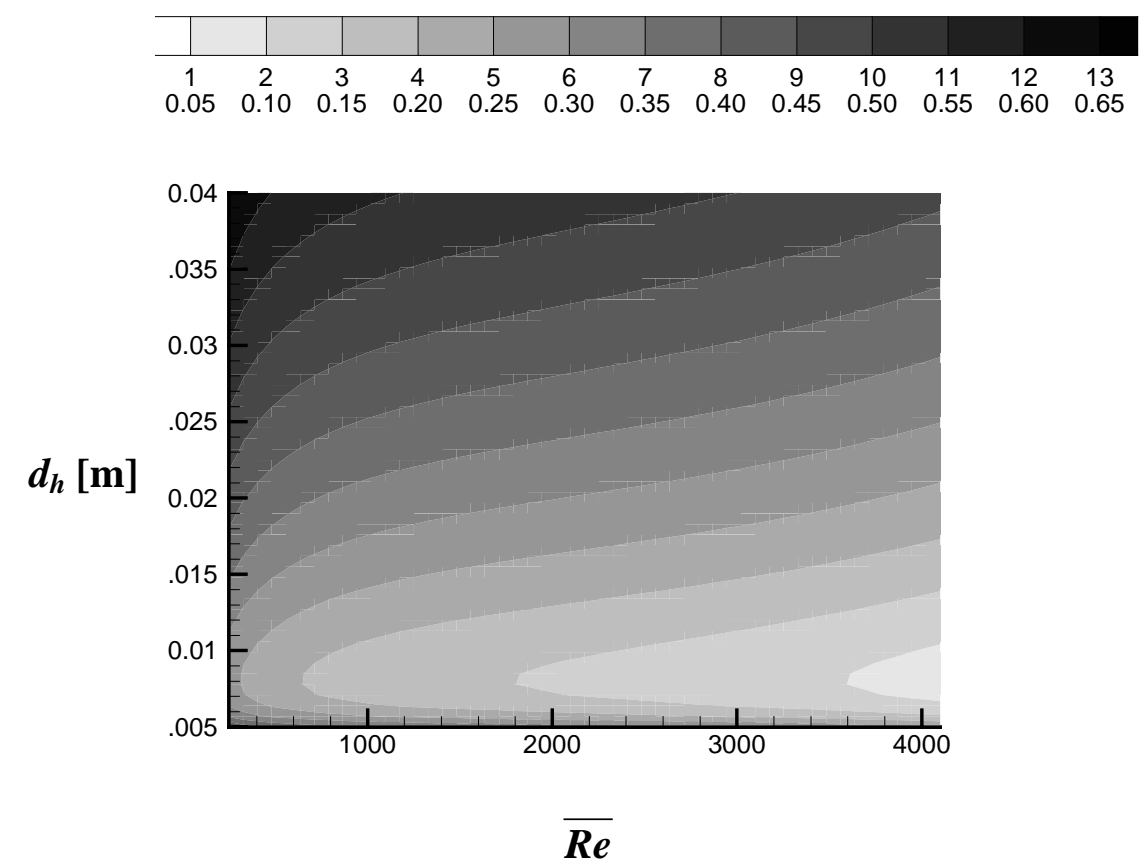

Figure 6: Drag coefficient polynomial function (19) for the wing-shaped tubes.

Figures 4-6 show that for all three tested forms, $\bar{C}_{d}$ monotonically decreases with $\overline{R e}$ for any given $d_{h}$. If a value of $\overline{R e}$ is set, $\bar{C}_{d}$ has its minimum for an unique value of $d_{h}$. This value of the hydraulic diameter $d_{h}$ is higher for the cylindrical and the ellipsoidal tubes $(\sim 0.012 \mathrm{~m})$ than for the wing form of tubes $(\sim 0.0075 \mathrm{~m})$. The comparison of the contour plots in Figs. 4-6 shows that the lowest values of $\bar{C}_{d}$ are found for the wing-shaped tubes, although this region is very narrow. Namely, the $\bar{C}_{d}$ function is much steeper for the wing-shaped tubes than for the cylindrical and the ellipsoidal tubes. This is related to a very complex flow behavior that was observed in the wing-shaped tube bundles for larger values of the hydraulic diameter $d_{h \text {. }}$ or when the spacing between the tubes is increased.

Figures 7-10 present comparison between the polynomial functions $\bar{C}_{d}\left(d_{h}, \overline{R e}\right)$ and the discrete values of $\bar{C}_{d}$ that were obtained from the time distributions (15) for all three tested forms. In general, the constructed polynomial functions (17-19), give a good approximation of the discrete 
values. Larger discrepancies exist only for the wing-shaped tubes with $p / d=1.5$ and at higher values of $\overline{\operatorname{Re}}$ (Fig. 9).

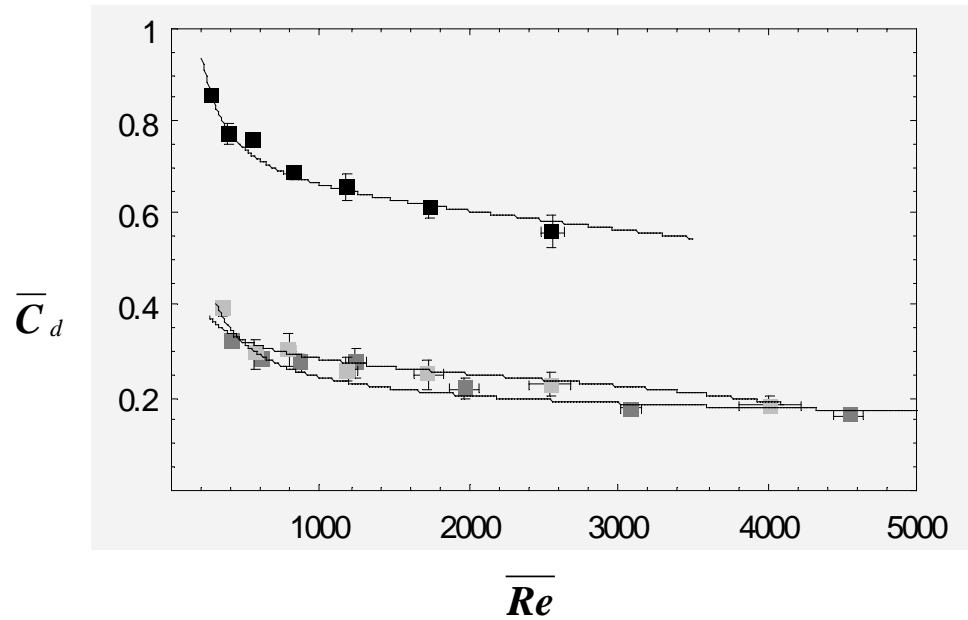

- cylindrical tubes

- ellipsoidal tubes

wing form tubes

Figure 7: Comparison of the drag coefficient polynomial functions with the calculated average drag coefficient values for the cylindrical $\left(d_{h}=0.5824 \mathrm{~cm}\right)$, the ellipsoidal $\left(d_{h}=0.5649 \mathrm{~cm}\right)$ and the wing-shaped $\left(d_{h}=0.5413 \mathrm{~cm}\right)$ tubes; $p / d=1.125$.

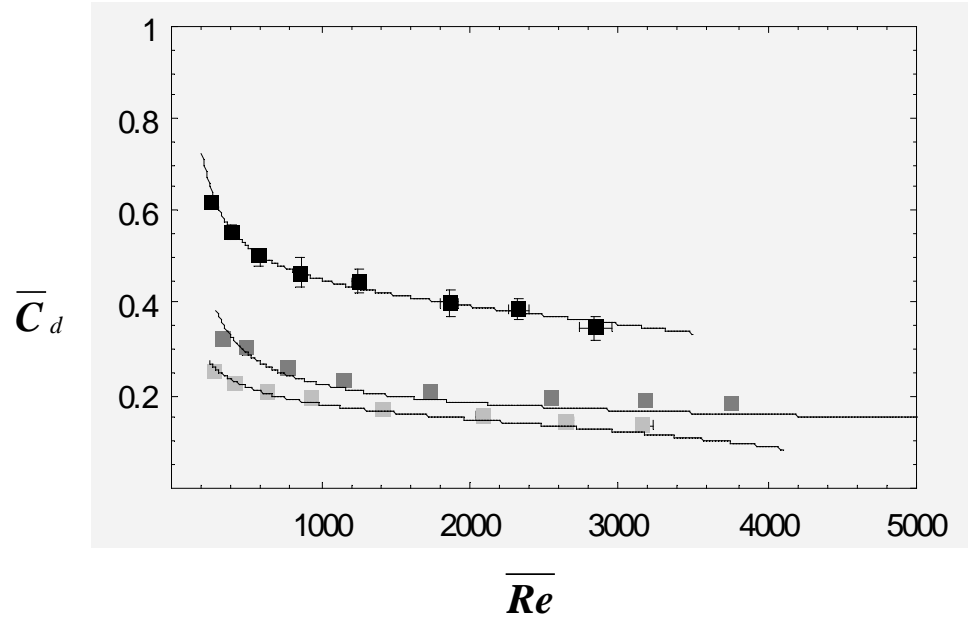

- cylindrical tubes

ellipsoidal tubes

wing form tubes

Figure 8: Comparison of the drag coefficient polynomial functions with the calculated average drag coefficient values for the cylindrical $\left(d_{h}=0.9424 \mathrm{~cm}\right)$, the ellipsoidal $\left(d_{h}=0.9142 \mathrm{~cm}\right)$ and the wing-shaped $\left(d_{h}=0.7382 \mathrm{~cm}\right)$ tubes; $p / d=1.25$. 


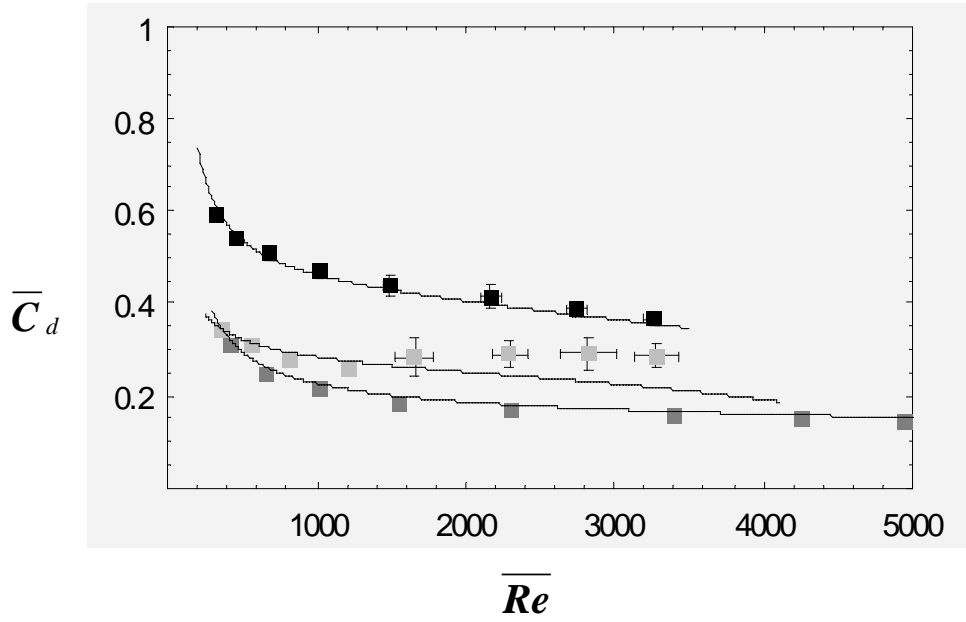

- cylindrical tubes

- ellipsoidal tubes

wing form tubes

Figure 9: Comparison of the drag coefficient polynomial functions with the calculated average drag coefficient values for the cylindrical $\left(d_{h}=1.776 \mathrm{~cm}\right)$, the ellipsoidal $\left(d_{h}=1.723 \mathrm{~cm}\right)$ and the wing-shaped $\left(d_{h}=1.638 \mathrm{~cm}\right)$ tubes; $p / d=1.5$.

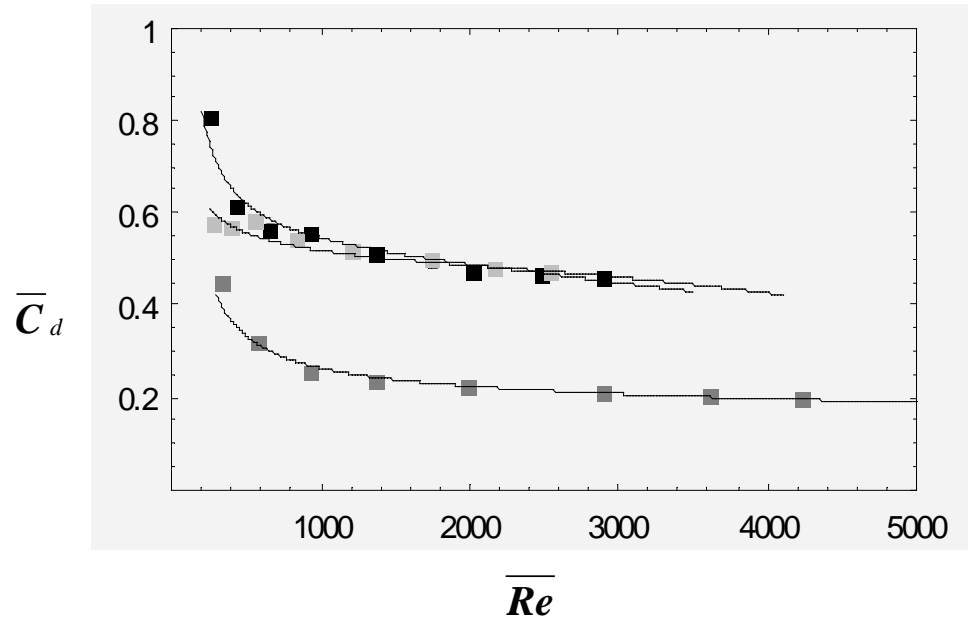

- cylindrical tubes

ellipsoidal tubes

wing form tubes

Figure 10: Comparison of the drag coefficient polynomial functions with the calculated average drag coefficient values for the cylindrical $\left(d_{h}=3.899 \mathrm{~cm}\right)$, the ellipsoidal $\left(d_{h}=3.782 \mathrm{~cm}\right)$ and the wing-shaped $\left(d_{h}=3.594 \mathrm{~cm}\right)$ tubes; $p / d=2.0$.

At Reynolds number of a few hundreds, the airflow is still laminar and the steady-state conditions are reached. In this laminar region, $\bar{C}_{d}$ decreases with increasing $\overline{R e}$ much faster than in the turbulent region (Figs. 7-10). The transition between laminar and turbulent flow is usually accompanied with strong flow oscillations, which consequently increase $\bar{C}_{d}$. The flow 
periodically changes direction and the spanwise motion of the fluid becomes important. At small values of $d_{h}$ (Figs. 7 and 8), the cylindrical tubes produce much more drag than the ellipsoidal and the wing-shaped tubes. As the spacing between the tubes increases, the difference between the drag coefficient functions becomes smaller. Due to the fast build-up of fluid spanwise motion in the tube arrays with the wing form cross-sections, the calculated drag coefficient $\bar{C}_{d}$ increases and at the pitch-to-diameter ratio $p / d=2.0$ it reaches similar values than those obtained for the cylindrical tubes (Fig. 10).

Large oscillations were observed in the tube bundle with the wing-shaped tubes at the pitch-todiameter ratio $p / d=1.5$. These oscillations are characterized by the separation of the boundary layer on the tube walls. It seems that a specific location of the separation triggers strong unsteady spanwise streams that increase $\bar{C}_{d}$. Similar behavior of the drag coefficient can be observed also in the diagrams of the experimental data for the ellipsoidal tubes recorded by Keys and London (1998).

\subsection{Stanton number functions}

Similarly, using the recorded time distributions of Stanton number $S t(t)$, the time averages $\overline{S t}$ were calculated for the cylindrical, the ellipsoidal and the wing-shaped tubes and for the all imposed pressure drops. Based on the calculated time averages $\overline{S t}$, the Stanton number approximation functions $\overline{S t}\left(d_{h}, \overline{R e}\right)$ were determined using least-square polynomial regression. The following Stanton number approximation functions were obtained: 
- Cylindrical tubes

$$
\begin{aligned}
\overline{S t}\left(d_{h}, \overline{R e}\right)=-0.02388 & +6.774 \cdot 10^{-12} d_{h}^{-4}-0.01714 d_{h}^{1 / 2}+6.553 \sqrt{d_{h} / \operatorname{Re}} \\
& +2.090 \cdot 10^{-7} \overline{\operatorname{Re}}^{-3}+1.271 \overline{\operatorname{Re}}{ }^{-1 / 2}+7.999 \cdot 10^{-6} \overline{\operatorname{Re}}-2.945 \cdot 10^{-13} \overline{\operatorname{Re}}^{3}
\end{aligned}
$$

- Ellipsoidal tubes

$$
\begin{aligned}
\overline{S t}\left(d_{h}, \overline{R e}\right)= & 0.03716+1.529 \cdot 10^{-10} d_{h}^{-3}-5.155 \cdot 10^{-5} d_{h}^{-1}+0.02325 d_{h}^{1 / 2} \\
& +105.9 \sqrt{d_{h}} / R e+0.7523 \overline{\operatorname{Re}}^{-1}+2.804 \cdot 10^{-4} \overline{\operatorname{Re}} \bar{R}^{1 / 2}
\end{aligned}
$$

- Wing-shaped tubes

$$
\begin{aligned}
\overline{S t}\left(d_{h}, \overline{R e}\right)=-0.01863+1.331 \cdot 10^{-11} d_{h}^{-4}+0.1185 d_{h}^{1 / 2}+9.180 \sqrt{d_{h} / \operatorname{Re}} \\
+0.2078 \overline{\operatorname{Re}^{-1 / 2}}+3.271 \cdot 10^{-7} \overline{\operatorname{Re}}-2.530 \cdot 10^{-15} \overline{\operatorname{Re}}^{3}
\end{aligned}
$$

Figures 11-13 present contour plots of the Stanton number polynomials for the cylindrical (20), the ellipsoidal (21) and the wing-shaped (22) tubes.
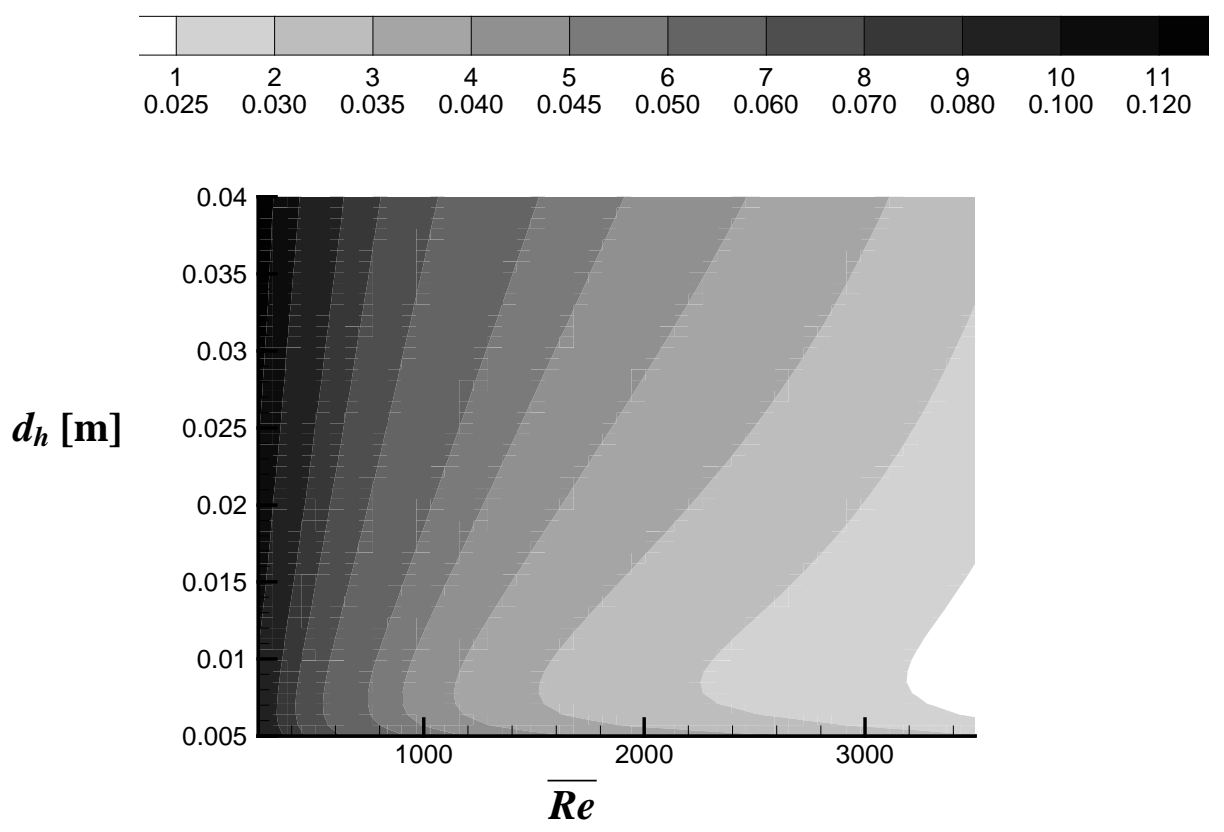

Figure 11: Stanton number polynomial function (20) for the cylindrical tubes. 


\begin{tabular}{c|c|c|c|c|ccccccc|}
\hline & & & & & & & & & & & \\
\hline 1 & 2 & 3 & 4 & 5 & 6 & 7 & 8 & 9 & 10 & 11 \\
0.015 & 0.020 & 0.025 & 0.030 & 0.035 & 0.040 & 0.045 & 0.050 & 0.060 & 0.070 & 0.080
\end{tabular}

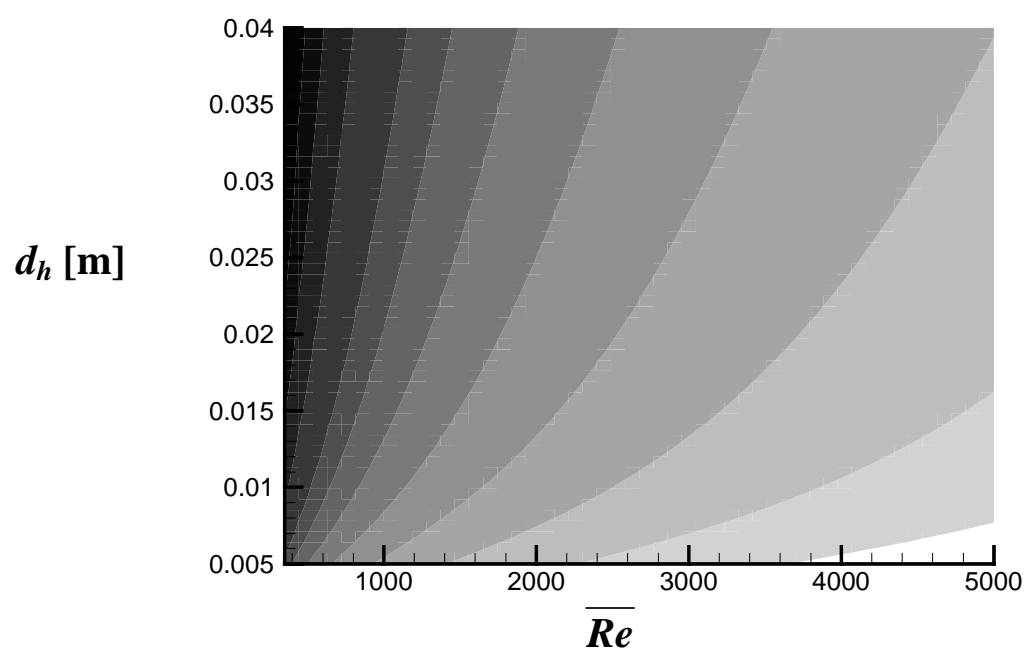

Figure 12: Stanton number polynomial function (21) for the ellipsoidal tubes.

\begin{tabular}{cccccccccccc}
\hline & & & & & & & & & & & \\
\hline 1 & 2 & 3 & 4 & 5 & 6 & 7 & 8 & 9 & 10 & 11 \\
0.015 & 0.020 & 0.025 & 0.030 & 0.035 & 0.040 & 0.050 & 0.060 & 0.080 & 0.100 & 0.120
\end{tabular}

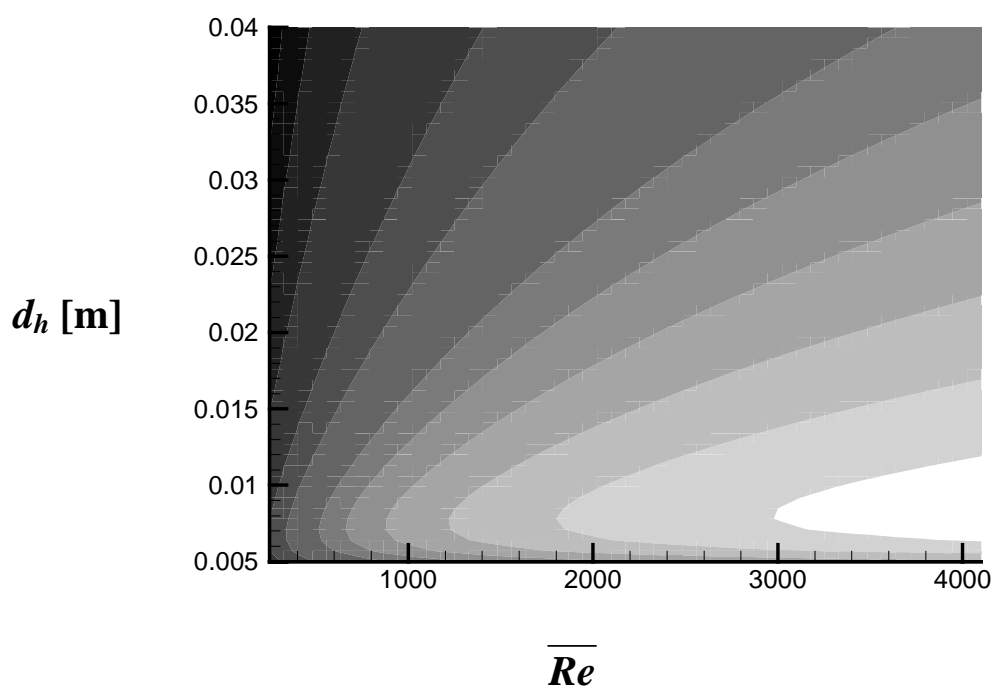

Figure 13: Stanton number polynomial function (22) for the wing-shaped tubes.

The shape of the Stanton number contour plots (Figs. 11-13) is similar to the shape of the drag coefficient contour plots (Figs. 4-6). The reason for this similarity is that in the range of considered Reynolds numbers the heat transfer crucially depends on the momentum transfer 
from the fluid flow to the structure walls. The Stanton number monotonically decreases with increasing $\overline{R e}$ for any given $d_{h}$. This means that the flow velocity increases faster than the convective heat transfer from the isothermal walls to the fluid. Therefore, the average fluid temperature $T_{f}(t)$, as defined by (13), decreases with increasing $\overline{R e}$. Like the drag coefficient $\bar{C}_{d}$, also the Stanton number $\overline{S t}$ experiences a minimum at an unique value of the hydraulic diameter $d_{h}$ for a given value of $\overline{R e}$ - at small $d_{h}$ the Stanton number $\overline{S t}$ first rapidly decreases and then gradually increases with increasing $d_{h}$.

To get an impression how exactly the Stanton number polynomial functions (20-22) approximate the calculated discrete values $\overline{S t}$, Figs. $14-17$ present their comparison for all simulated cases. The constructed polynomial functions (20-22) give a satisfactory approximation of the discrete values. Larger differences can be only observed for the wing-shaped tubes at $p / d=1.5$ for larger values of $\overline{R e}$, where the flow oscillations occur.

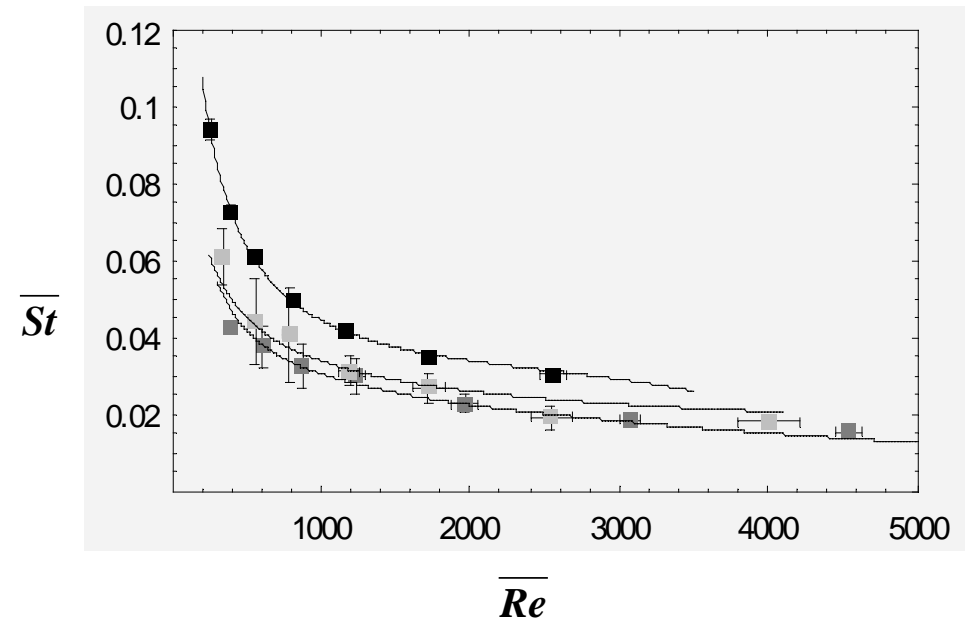

- cylindrical tubes

- ellipsoidal tubes

wing form tubes

Figure 14: Comparison of the Stanton number polynomial functions with the calculated average Stanton number values for the cylindrical $\left(d_{h}=0.5824 \mathrm{~cm}\right)$, the ellipsoidal $\left(d_{h}=0.5649 \mathrm{~cm}\right)$ and the wing-shaped $\left(d_{h}=0.5413 \mathrm{~cm}\right)$ tubes; $p / d=1.125$. 


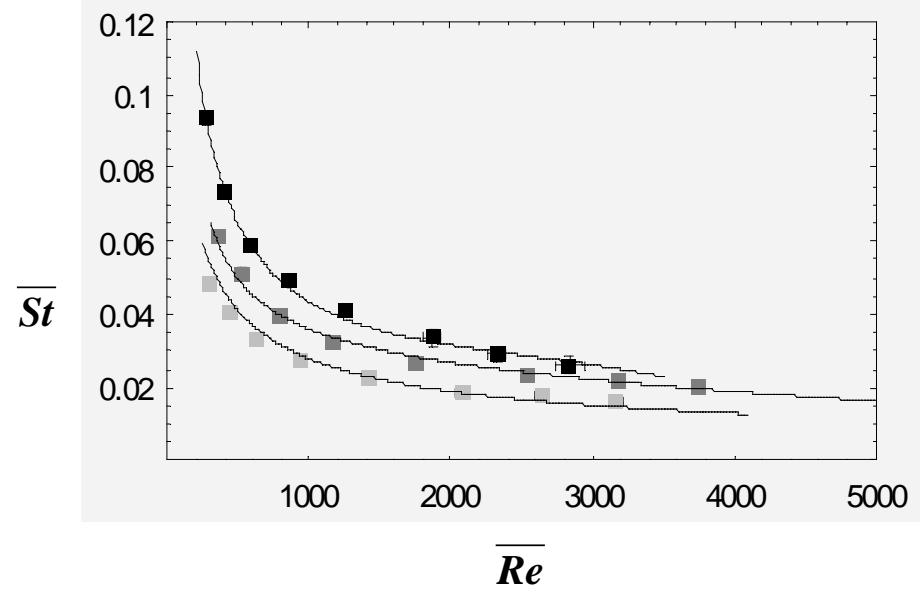

- cylindrical tubes

- ellipsoidal tubes

wing form tubes

Figure 15: Comparison of the Stanton number polynomial functions with the calculated average Stanton number values for the cylindrical $\left(d_{h}=0.9424 \mathrm{~cm}\right)$, the ellipsoidal $\left(d_{h}=0.9142 \mathrm{~cm}\right)$ and the wing-shaped $\left(d_{h}=0.7382 \mathrm{~cm}\right)$ tubes; $p / d=1.25$.

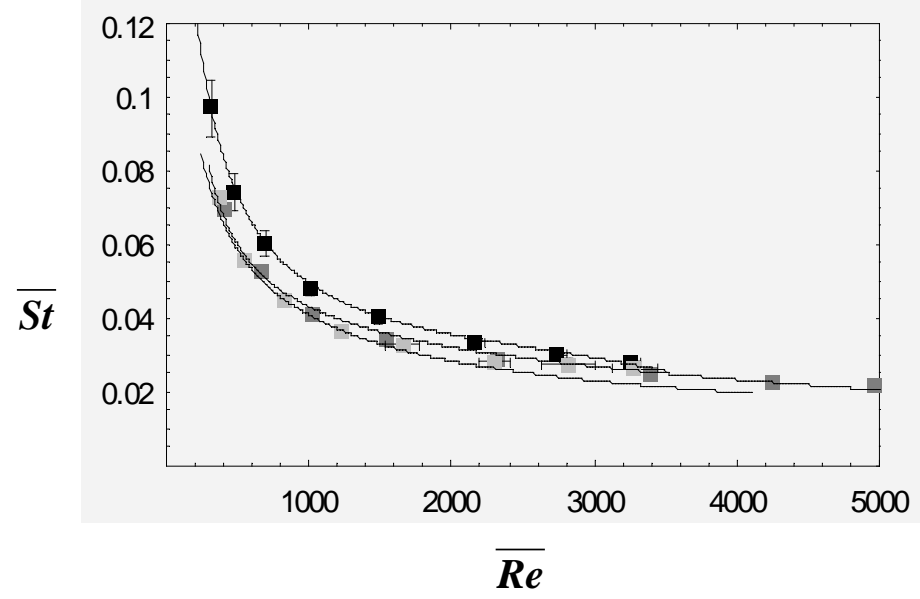

- cylindrical tubes

- ellipsoidal tubes

wing form tubes

Figure 16: Comparison of the Stanton number polynomial functions with the calculated average Stanton number values for the cylindrical $\left(d_{h}=1.776 \mathrm{~cm}\right)$, the ellipsoidal $\left(d_{h}=1.723 \mathrm{~cm}\right)$ and the wing-shaped $\left(d_{h}=1.638 \mathrm{~cm}\right)$ tubes; $p / d=1.5$. 


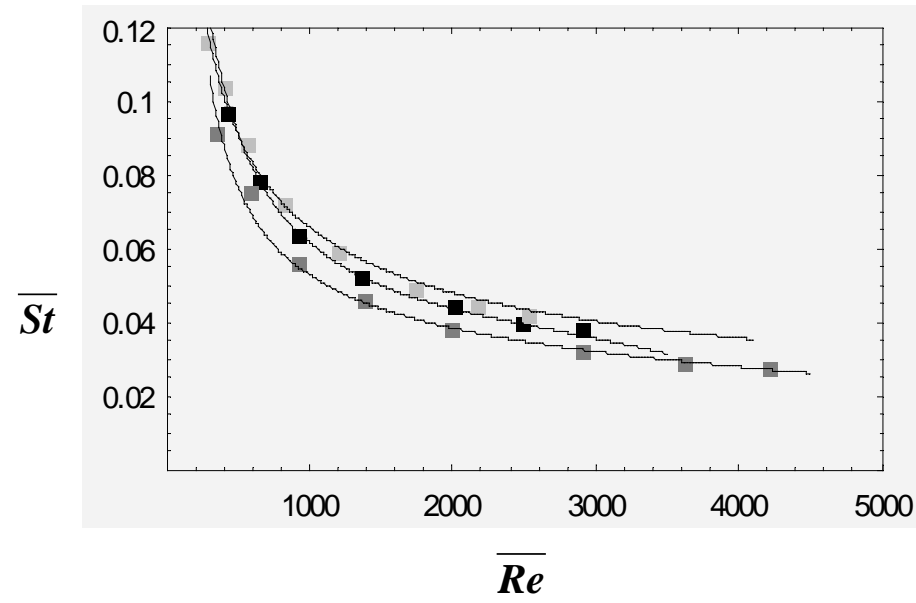

- cylindrical tubes

ellipsoidal tubes

wing form tubes

Figure 17: Comparison of the Stanton number polynomial functions with the calculated average Stanton number values for the cylindrical $\left(d_{h}=3.899 \mathrm{~cm}\right)$, the ellipsoidal $\left(d_{h}=3.782 \mathrm{~cm}\right)$ and the wing-shaped $\left(d_{h}=3.594 \mathrm{~cm}\right)$ tubes; $p / d=2.0$.

The Stanton number $\overline{S t}$ values show similar behavior as the drag coefficient $\bar{C}_{d}$ distributions; in the laminar region $\overline{S t}$ decreases faster with increasing $\overline{R e}$ than in the turbulent region. On the other hand, the transitional behavior that is evident from the calculated values of $\bar{C}_{d}$ (Figs. 7-10) shows almost no influence on the $\overline{S t}$ values. Figures 14-17 show that $\overline{S t}$ is larger for the cylindrical than for the ellipsoidal and the wing-shaped tubes. The difference between $\overline{S t}$ distributions is larger for small $d_{h}$ and it decreases as $p / d$ becomes larger.

\section{Conclusions}

Numerical analysis of heat transfer was performed for the heat exchanger segments with the cylindrical, the ellipsoidal and the wing-shaped tubes in the staggered arrangement. The purpose of the analysis was to get a detailed insight of the local heat transfer and fluid flow conditions in a heat exchanger and to establish widely applicable drag coefficient and Stanton number functions for the heat exchanger integral model (Horvat and Catton, 2003). 
Almost 100 three-dimensional transient numerical simulations were performed for the tube bundle cross-flow, considering different tube shapes, different pitch-to-diameter ratios and different flow Reynolds numbers. It is important to mention that we encountered a much more complex physical behavior than it was reported in the available literature (e.g. Bejan, 1995, Stanescu et al. 1996, and Matos et al., 2004). Large flow oscillations and semi-stochastic motion of the flow in the spanwise direction were observed as the flow regime changes, especially for the wing-shaped tubes.

From the statistical steady-state simulation results of the each analyzed case, the time distributions of the Reynolds number $\operatorname{Re}(t)$, the drag coefficient $C_{d}(t)$ and the Stanton number $S t(t)$ were obtained and their average values calculated. By comparing the calculated time average values of $\bar{C}_{d}$ and $\overline{S t}$ for the three considered tube shapes, some general conclusions on thermal performance can be drawn.

The general behavior of $\bar{C}_{d}$ and $\overline{S t}$ is similar for all three tube shapes. The drag coefficient $\bar{C}_{d}$ as well as the Stanton number $\overline{S t}$ monotonically decrease with increasing $\overline{R e}$ for any hydraulic diameter $d_{h}$. On the contrary, $\bar{C}_{d}$ and $\overline{S t}$ exhibit a minimum at a certain value of $d_{h}$ for any given $\overline{R e}$. In general, the values of $\bar{C}_{d}$ and $\overline{S t}$ are lower for the ellipsoidal and the wing-shaped tubes than for the cylindrical tubes.

The time average values $\overline{R e}, \bar{C}_{d}$ and $\overline{S t}$ were used to construct the polynomial functions $\bar{C}_{d}\left(d_{h}, \overline{R e}\right)$ and $\overline{S t}\left(d_{h}, \overline{R e}\right)$ for the cylindrical, the ellipsoidal and the wing-shaped tubes. The constructed $\bar{C}_{d}\left(d_{h}, \overline{R e}\right)$ and $\overline{S t}\left(d_{h}, \overline{R e}\right)$ functions are much stepper for the wing shaped tubes than for the cylindrical and the ellipsoidal tubes. Although, the differences between $\bar{C}_{d}\left(d_{h}, \overline{R e}\right)$ and 
$\overline{S t}\left(d_{h}, \overline{R e}\right)$ functions are large at small $d_{h}$, they become smaller as $d_{h}$ increases. This allows us to conclude that the influence of different forms of bounding surfaces diminishes with increasing $d_{h}$

\section{References}

Žukauskas, A.,1987, "Convective Heat Transfer in Cross Flow", Handbook of Single-Phase Convective Heat Transfer, Wiley \& Sons, New York.

Kays, W. S., London, A. L., 1998, "Compact Heat Exchangers", 3rd Ed., Krieger Publishing Company, Malabar, Florida.

Kakac, S., 1985, "Heat Exchangers: Thermo-Hydraulic Fundamentals and Design", 2nd Ed., Hemisphere Publishing.

Aiba, S., Tsuchida, H., Ota, T., 1982, "Heat Transfer Around Tubes in In-Line Tube Banks", Bulletin of the JSME, Vol. 25, No. 204, pp. 919-926.

Launder, B. E., Massey, T. H., 1978, "The Numerical Prediction of Viscous Flow and Heat Transfer in Tube Banks", J. Heat Transfer, Vol. 100, pp. 565-571.

Antonopoulos, K. A., 1979, "Prediction of Flow and Heat Transfer in Rod Bundles", Ph.D. Thesis, Mechanical Engineering Department, Imperial College, London, UK.

Beale, S. B., Spalding, D. B., 1999, "A Numerical Study of Unsteady Fluid Flow in In-Line and Staggered Tube Banks", J. Fluids and Structures, pp. 723-754. 
Barsamian, H. R., Hassan, Y. A, 1997, "Large Eddy Simulation of Turbulent Crossflow in Tube Bundles", Nuclear Engineering and Design Journal, Vol. 172, pp. 103-122.

Horvat, A., Mavko, B., 2005, "Hierarchic Modeling of Heat Transfer Processes in Heat Exchangers", Int. J. Heat Mass Transfer, 48, pp. 361-371.

Horvat, A., Catton, I., 2003, "Numerical Technique for Modeling Conjugate Heat Transfer in an Electronic Device Heat Sink", Int. J. Heat Mass Transfer, 46, pp. 2155-2168.

Ladson, C. L., Brooks, C. W. Jr., Hill, A. S., 1996, "Computer Program to Obtain Ordinates for NACA Airfoils", NASA Technical Memorandum 4741, Langley Research Center, Hampton, VA, USA.

Bird, R. B., Stewart, W. E., Lightfoot, E. N., 1960, "Transport Phenomena", Wiley, New York.

Menter, F. R., 1993, "Zonal Two-Equation k- $\omega$ Turbulence Models for Aerodynamic Flows", AIAA 93-2906.

Wilcox, D. C., 1986, "Multiscale Model for Turbulent Flows", AIAA 24th Aerospace Sciences Meeting, American Institute of Aeronautics and Astronautics, Proceedings, p. 37.

Menter, F. R., 1994, "Two-Equation Eddy-Viscosity Turbulence Models for Engineering Applications", AIAA-Journal, Vol. 32, No. 8, pp. 37- 40.

Bejan, A., 1995, "Convection Heat Transfer", 2nd Ed., John Wiley \& Sons Inc, New York. 
Stanescu, G., Fowler, A. J., Bejan, A., 1996, "The Optimal Spacing of Cylinders in Free-Stream Cross-Flow Forced Convection", Int. J. Heat Fluid Flow, Vol. 39, No. 2, pp. 311-317.

Matos, R. S., Vergas, J. V. C., Laursen, T. A., Bejan, A., 2004, "Optimally Staggered Finned Circular and Elliptic Tubes in Forced Convection", Int. J. Heat Fluid Flow, Vol. 47, pp. $1347-1359$.

\section{Acknowledgements}

A. Horvat gratefully acknowledges the financial support received from the Ministry of Higher Education, Science and Technology of Republic of Slovenia under the project "Determination of morphological parameters for optimization of heat exchanger surfaces". 